\title{
Changes in left anterior descending coronary artery flow profiles after coronary artery bypass grafting examined by means of transthoracic Doppler echocardiography
}

\author{
Masao Yoshitatsu, MD \\ Yuji Miyamoto, MD \\ Masataka Mitsuno, MDa \\ Koichi Toda, MDa \\ Masato Yoshikawa, MD \\ Shinya Fukui, MD \\ Fumikazu Nomura, $\mathrm{MD}^{\mathrm{b}}$ \\ Nobuaki Hirata, MD ${ }^{\mathrm{c}}$ \\ Kenji Onishi, MD
}

From the Division of Cardiovascular Surgery, ${ }^{\text {a }}$ Sakurabashi-Watanabe Hospital, Osaka, Japan; the Division of Cardiovascu-

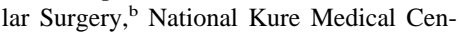
ter, Hiroshima, Japan; and the Division of Cardiovascular Surgery, ${ }^{\mathrm{c}}$ Takarazuka City Hospital, Hyogo, Japan.

Received for publication Sept 15, 2002; revisions requested Oct 16, 2002; revisions received Oct 24, 2002; accepted for publication Nov 1, 2002

Address for reprints: Masao Yoshitatsu, MD, Division of Cardiovascular Surgery, National Kure Medical Center, 3-1, Aoyama, Kure, Hiroshima 737-0023, Japan (E-mail: yoshitatsu @kure-nh.go.jp).

J Thorac Cardiovasc Surg 2003;126:1531-6

Copyright (C) 2003 by The American Association for Thoracic Surgery

$0022-5223 / 2003 \$ 30.00+0$

doi:10.1016/S0022-5223(03)00972-3
Objective: We sought to investigate the changes of velocity profiles in the left anterior descending coronary artery after coronary artery bypass grafting using transthoracic Doppler echocardiography.

Methods: Forty-five patients who received a bypass graft to the left anterior descending coronary artery were studied. Before coronary artery bypass grafting, Doppler velocity profiles of the distal left anterior descending coronary artery were recorded with transthoracic Doppler echocardiography. Peak systolic velocity, mean systolic velocity, peak diastolic velocity, mean diastolic velocity, total velocity time integral, systolic velocity time integral, and diastolic velocity time integral were measured. Three weeks after coronary artery bypass grafting, left anterior descending coronary artery antegrade flow in the distal portion of the anastomosis was obtained by using the same method. Coronary angiography was performed before and 3 weeks after coronary artery bypass grafting.

Results: The overall success rate of measuring the left anterior descending coronary artery flow was $60.0 \%$ preoperatively and $80.0 \%$ postoperatively. In 25 patients, in whom all parameters were obtained both before and after coronary artery bypass grafting, the following increased significantly after coronary artery bypass grafting: peak systolic velocity $(14.86 \pm 7.50$ vs $25.07 \pm 17.02 \mathrm{~cm} / \mathrm{s}, P=.0045)$, mean systolic velocity $(9.86 \pm 5.42$ vs $18.03 \pm 12.94 \mathrm{~cm} / \mathrm{s}, P=.0026)$, peak diastolic velocity $(24.26 \pm 12.54 \mathrm{vs} 48.28 \pm 31.66 \mathrm{~cm} / \mathrm{s}, P=.0021)$, mean diastolic velocity $(14.94 \pm 6.65$ vs $30.36 \pm 20.71 \mathrm{~cm} / \mathrm{s}, P=.0022)$, diastolic velocity time integral $(7.22 \pm 2.88$ vs $15.55 \pm 10.39 \mathrm{~cm}, P=.0009)$, total velocity time integral $(10.50$ \pm 4.48 vs $19.27 \pm 12.63 \mathrm{~cm}, P=.0034)$, and diastolic-to-systolic velocity time integral ratio $(3.09 \pm 1.53$ vs $4.97 \pm 2.75, P=.0044)$. Angiography showed graft patency and no significant change in left anterior descending coronary artery stenosis in all patients.

Conclusions: Transthoracic Doppler echocardiography showed a significant increase in some parameters in left anterior descending coronary artery flow after coronary artery bypass grafting. Measurement of left anterior descending coronary artery flow by means of transthoracic Doppler echocardiography might be a noninvasive method to evaluate the effect of bypass grafting on the left anterior descending coronary artery. 


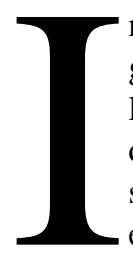

n many patients undergoing coronary artery bypass grafting $(\mathrm{CABG})$, low blood flow in the recipient left anterior descending coronary artery (LAD) induces severe heart failure and affects postoperative survival. If a noninvasive and reliable method to evaluate myocardial perfusion in the grafted LAD region was possible, it could help in determining further treatment for patients with heart failure after CABG. Transthoracic Doppler echocardiography (TTDE) is noninvasive, relatively inexpensive, and widely used in this clinical setting. In particular, in a critical condition in which invasive examinations, such as coronary angiography or myocardial scintigraphy, are not available, TTDE is a very useful method. Recent technologic advancement in TTDE provides measurements of coronary flow in the distal portion of the LAD. ${ }^{1-13}$ To the best of our knowledge, however, little is known about changes in the LAD flow profiles after CABG. The objective of this study was to clarify changes in LAD flow profiles after CABG by using TTDE and to evaluate the value of TTDE as a noninvasive method for assessing the effect of bypass grafting on the LAD immediately after CABG.

\section{Methods}

\section{Patients}

The study group consisted of 45 consecutive patients who received a bypass graft to the LAD at Sakurabashi-Watanabe Hospital during the period of August 2000 to August 2001. The study population comprised 36 men and 9 women with ages ranging from 46 to 81 years (mean, $65.7 \pm 7.3$ years) and with ischemic heart disease and significant stenosis in the proximal portion of the LAD or the left main trunk of the coronary artery. Bypass grafting was performed to the midportion of the LAD. The bypass grafts to the LAD consisted of 33 left internal thoracic arteries (ITAs) in situ, 9 right ITAs in situ, 2 radial arteries, and 1 free ITA. Off-pump coronary artery bypass grafting (OPCAB) was performed in 10 patients. Emergency operations were performed in 9 patients. During conventional CABG, myocardial protection was achieved with topical cold saline and intermittent cold blood cardioplegia, followed by terminal warm blood cardioplegia. During OPCAB, a 3-minute period of ischemic preconditioning was performed, and the shunt tube was used in some cases. The characteristics of all patients are shown in Table 1. All patients underwent coronary angiography within 2 months before the operation to evaluate LAD stenosis. Postoperative graft patency and LAD stenosis were evaluated by means of coronary angiography 3 weeks after the operation. Each patient gave informed consent to the study protocol, which was approved by the Committee for the Protection of Human Subjects in Research at Sakurabashi-Watanabe Hospital.

\section{Transthoracic Echocardiography}

Echocardiography was performed 1 week before CABG and 3 weeks after CABG. Echocardiography was performed in the left lateral decubitus by using a multifrequency transducer, which allowed online changes of frequency to be seen separately in

\section{TABLE 1. Characteristics of all patients}

\begin{tabular}{lc}
\hline No. (male/female) & 45 (36/9) \\
Age (y) & $65.7 \pm 7.3$ (range, 46-81) \\
Graft to LAD & \\
LITA & 33 (in situ) \\
& 1 (free graft) \\
RITA & 9 (in situ) \\
RA & 2 \\
Graft No. & $2.8 \pm 1.2$ (range, 1-5) \\
OPCAB & 10 \\
Emergency operation & 9 \\
Combined procedure & AVR: 1 , Dor procedure: 2
\end{tabular}

LITA, Left ITA; RITA, right ITA; $R A$, radial artery; $A V R$, aortic valve replacement.

2-dimensional imaging and color Doppler scanning (5-12 MHz). The transducer was connected to a Hewlett-Packard SONOS 5500 digital ultrasound system. To image the distal LAD, the transducer was placed either at the cardiac apex or the first intercostal space higher and focused on the proximal field. The ultrasound beam was angled laterally and superiorly to identify the anterior interventricular sulcus. The color gain was adjusted to provide optimal images. By using combined imaging and color flow mapping, the distal LAD was identified as a tubular structure located within the anterior interventricular sulcus and containing characteristic Doppler flow signals.

Blood flow velocity was measured by means of pulsed Doppler scanning. The spectral Doppler scan of the LAD flow showed a characteristic biphasic flow pattern with a large diastolic component and a small systolic component (Figure 1). The angle between the blood flow and ultrasonic beam was optimized and adequately corrected if necessary. Velocity measurements were performed by using the internal analysis package on the ultrasound unit. Seven parameters were measured by tracing the contour of the Doppler velocity pattern: (1) peak systolic velocity; (2) peak diastolic velocity; (3) mean systolic velocity; (4) mean diastolic velocity; (5) systolic velocity time integral (VTI); (6) diastolic VTI; and (7) total VTI. The diastolic-to-systolic velocity ratio was computed as the ratio of diastolic-to-systolic mean and peak coronary flow velocities. The diastolic-to-systolic VTI ratio was also computed. Before CABG, measurements were performed in the distal coronary artery. After the operation, recipient LAD flow was measured at a position distal to the anastomotic site of the bypass graft.

\section{Coronary Angiography}

All patients underwent coronary angiography within 2 months before the operation. Postoperative graft patency was confirmed by means of coronary angiography 3 weeks after the operation. Coronary angiography for all patients was performed by using the standard Judkin's technique with the single-plane imaging system.

\section{Statistical Analysis}

Statistical analysis was performed with the StatView software package, version 5.0 (Abacus Concepts, Inc). All values are expressed as means $\pm \mathrm{SD}$. A paired $t$ test was used to evaluate changes in each parameter after surgical intervention. An unpaired $t$ test was used to evaluate differences in each parameter between 

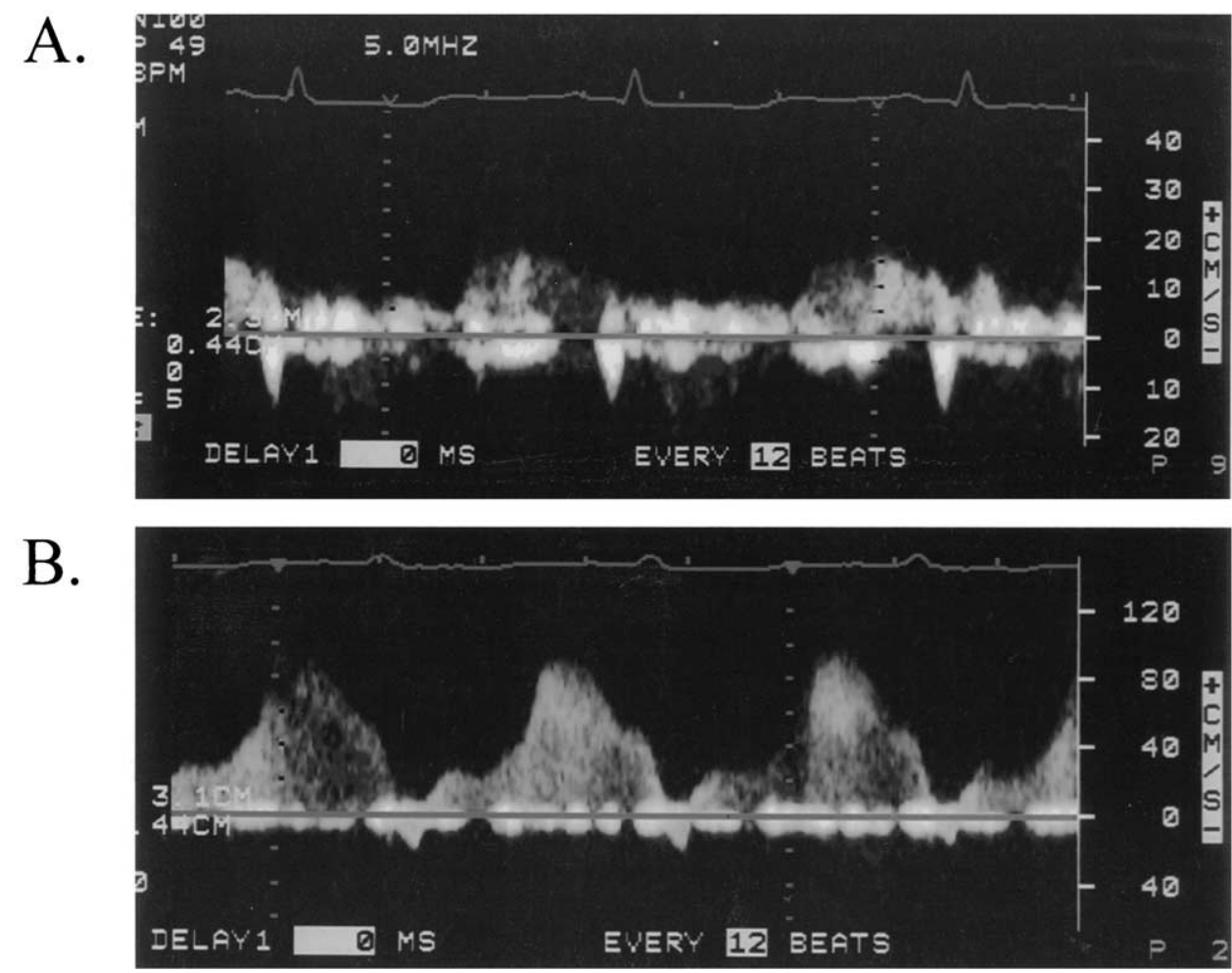

Figure 1. Spectral Doppler flow before (A) and after (B) CABG in the distal LAD.

2 groups (conventional CABG vs OPCAB). Comparison between the 2 groups was analyzed by using the $\chi^{2}$ method or the Fischer exact test for categoric variables.

\section{Results}

\section{Angiographic Assessment}

Postoperative angiography showed no stenosis at the anastomotic sites in all patients. In no case was either significant regression or progression of LAD stenosis detected.

\section{Echocardiographic Detection of LAD}

Doppler velocity profiles and diameters of the LAD were obtained in $27(60.0 \%)$ of 45 patients preoperatively and in $36(80.0 \%)$ of 45 patients postoperatively. All patients were assigned to one of 4 groups to clarify the factors affecting the ability of the LAD to be detected (Table 2). We considered that in group B, in which LAD was not detected preoperatively but rather detected postoperatively, the LAD flow was too small to be detected preoperatively and increased enough to be detected after successful CABG. We divided groups A and B into 2 subgroups: a severe stenosis group consisting of patients with severe stenosis (percent diameter stenosis $\geq 99 \%$ ) in the proximal LAD or the left main trunk and a nonsevere stenosis group of patients without severe stenosis in either the proximal LAD or the left main trunk (Table 3). The rate of severe stenosis in group B was significantly higher than that in group A $(P<$
TABLE 2. LAD detectability

\begin{tabular}{lllc}
\hline Subgroup & Before CABG & After CABG & Patient no. \\
\hline Group A & Detected & Detected & 25 \\
Group B & Not detected & Detected & 11 \\
Group C & Detected & Not detected & 2 \\
Group D & Not detected & Not detected & 7 \\
Total & & & 45
\end{tabular}

The success rate for detecting the LAD flow by means of TTDE was $60.0 \%$ (27/45) preoperatively and $80.0 \%(36 / 45)$ postoperatively.

.005). Before emergency operations, the patient's condition was thought unsuitable for meticulous measurement by means of TTDE. Therefore we analyzed the relationship of the ability of the LAD to be detected preoperatively to the requirement for emergency operation. All groups were divided into 2 subject groups: one group consisting of patients with emergency operations and the other consisting of patients with elective operations (Table 4). There was no significant difference in the ratio of emergency operation between group A plus $\mathrm{C}$ in which LAD was detected preoperatively and group B plus D in which the LAD was not detected preoperatively. There were 13 patients with total occlusions of the left main trunk or LAD. In these patients LAD flow was detected in 4 (30.8\%) patients, consisting of 3 with antegrade flow and 1 with retrograde flow. In group 
TABLE 3. Detectability of LAD flow versus severity of LAD stenosis

\begin{tabular}{lcr}
\hline Severe stenosis & $(+)$ & $(-1$ \\
\hline Group A & 7 & 18 \\
Group B & 9 & 2
\end{tabular}

Data are presented as the number of patients. The severe stenosis $(+)$ group consisted of patients with severe stenosis (percent diameter stenosis $(\geq 99 \%)$ in the proximal LAD or the left main trunk. The rate of severe stenosis group in group $\mathrm{B}$ was significantly higher than that in group $\mathrm{A}(P$ $<.005)$.

TABLE 4. Detectability of LAD flow versus emergency operation

\begin{tabular}{lcc}
\hline Operation & Emergency & Elective \\
\hline Group A + C (detected) & 4 & 23 \\
Group B + D (not detected) & 5 & 13
\end{tabular}

Data are presented as the number of patients. There was no significant difference in the ratio of emergency operation between group $A+C$, in which $L A D$ was detected before $C A B G$, and group $B+D$ in which $L A D$ was not detected after CABG.

A all parameters were obtained both preoperatively and postoperatively. The characteristics of group A (25 patients) are shown in Table 5, and the comparison of preoperative and postoperative values is shown in Table 6. Peak systolic velocity, mean systolic velocity, peak diastolic velocity, mean diastolic velocity, diastolic VTI, and total VTI increased significantly after CABG. (In the patient with total occlusion of the left main trunk, preoperative antegrade LAD flow was considered to be 0 .) On the other hand, the systolic VTI did not differ after CABG. Neither peak nor mean diastolic-to-systolic velocity ratios differed significantly after CABG, whereas the diastolic-to-systolic VTI ratio increased significantly after CABG.

In addition, we separated the patients undergoing OP$\mathrm{CAB}$ from the patients undergoing conventional $\mathrm{CABG}$ and examined whether there were any differences in LAD flow after bypass grafting by using these 2 different techniques. We compared the values of parameters that showed a significant increase after CABG. The results are shown in Table 7. We found no significant differences in any parameters before and after CABG. However, we also found a trend showing that the degree of increase was greater after conventional $\mathrm{CABG}$ than after OPCAB in all parameters.

\section{Discussion}

The purpose of this study was to clarify changes in LAD flow profiles after CABG by using TTDE and to evaluate the value of TTDE as a noninvasive method to assess the effect of bypass grafting on the LAD.
TABLE 5. Characteristics of patients with complete data before and after CABG (group A)

\begin{tabular}{lc}
\hline No. (male/female) & $25(20 / 5)$ \\
Age (y) & $65.0 \pm 7.4$ (range, 53-80) \\
Graft to LAD & \\
LITA & 20 (in situ) \\
RITA & 4 (in situ) \\
RA & 1 \\
Graft no. & $2.5 \pm 1.1$ (range, 1-5) \\
OPCAB & 8 \\
Emergency operation & 3
\end{tabular}

Data are presented as the number of patients or mean values \pm SD. LITA, Left ITA; RITA, right ITA; $R A$, radial artery.

TABLE 6. Parameters before and after CABG in group $A$ (n $=25$ )

\begin{tabular}{lccc}
\hline Variables & Before CABG & After CABG & $\boldsymbol{P}$ value \\
\hline PSV $(\mathrm{cm} / \mathrm{s})$ & $14.86 \pm 7.50$ & $25.07 \pm 17.02$ & .0045 \\
MSV $(\mathrm{cm} / \mathrm{s})$ & $9.86 \pm 5.42$ & $18.03 \pm 12.94$ & .0026 \\
PDV $(\mathrm{cm} / \mathrm{s})$ & $24.26 \pm 12.54$ & $48.28 \pm 31.66$ & .0021 \\
MDV $(\mathrm{cm} / \mathrm{s})$ & $14.94 \pm 6.65$ & $30.36 \pm 20.71$ & .0022 \\
SVTI $(\mathrm{cm})$ & $3.28 \pm 2.89$ & $3.72 \pm 2.44$ & .53 \\
DVTI $(\mathrm{cm})$ & $7.22 \pm 2.88$ & $15.55 \pm 10.39$ & .0009 \\
TVTI $(\mathrm{cm})$ & $10.50 \pm 4.48$ & $19.27 \pm 12.63$ & .0034 \\
PDSVR & $1.81 \pm 0.79$ & $2.15 \pm 1.03$ & .21 \\
MDSVR & $1.66 \pm 0.56$ & $1.83 \pm 0.57$ & .27 \\
DSVTIR & $3.09 \pm 1.53$ & $4.97 \pm 2.75$ & .0044 \\
\hline
\end{tabular}

Data are presented as mean \pm SD. PSV, Peak systolic velocity; $M S V$, mean systolic velocity; $P D V$, peak diastolic velocity; $M D V$, mean diastolic velocity; SVTI, systolic VTI; DVTI, diastolic VTI; TVTI, total VTI; PDSVR, peak diastolic-to-systolic velocity ratio; $M D S V R$, mean diastolic-to-systolic velocity ratio; DSVTIR, diastolic-to-systolic VTI ratio.

\section{Changes in LAD Flow Profiles After CABG}

In our study there were significant changes in diastolic VTI, despite no significant changes in systolic VTI. Thus the diastolic-to-systolic VTI ratio increased significantly after CABG. It is presumed that these data indicate the improvement of myocardial perfusion during diastole by CABG. In normal coronary arteries most blood flow occurs during diastole because myocardial compression during systole increases distal vascular resistance. ${ }^{13}$

There have been few reports about diastolic VTI and systolic VTI of the LAD by TTDE. Crowley and Shapiro ${ }^{13}$ reported that in the normal LAD mean systolic VTI was 3.5 $\pm 1.9 \mathrm{~cm}$ and mean diastolic VTI was $11.7 \pm 6.5 \mathrm{~cm}$. It might be thought that these data are as great as our postoperative data. It appears that a graft to the LAD provides enough flow to the ischemic myocardium. On the other hand, our data also showed that the peak and mean diastolic velocities and systolic velocities increased significantly postoperatively. Thus there were no significant changes in the peak diastolic-to-systolic velocity ratio and mean diastolic-to-systolic velocity ratio. It is reported that the dias- 
tolic-to-systolic coronary flow velocity ratio in the distal coronary artery provides important information on stenosis in the proximal coronary artery. ${ }^{7,8}$ Higashiue and colleagues ${ }^{7}$ reported that both peak and mean diastolic velocities significantly increased after successful coronary angioplasty, and there was no significant change in either peak systolic velocity or mean systolic velocity. Because multiple flow of grafts and native other coronaries would affect LAD flow in patients after CABG, LAD flow characteristics would differ from those in patients after angioplasty only to the LAD. Related to the small sample size of our patient population, further studies involving larger data sets are needed to confirm these results.

\section{TTDE as a Noninvasive Method to Assess Myocardial Perfusion After CABG}

In this study the success rate for the detection of LAD flow by means of TTDE was $60.0 \%$ preoperatively and $80.0 \%$ postoperatively. The preoperative success rate was lower than that reported by other investigators, ${ }^{1-13}$ and the postoperative success rate was high enough for clinical applications. As described in the "Results" section, the principal factor contributing to a lower success rate preoperatively was severe stenosis in the native coronary artery. In our study the rate of successful detection of LAD flow in the patients with total occlusion of the LAD or the left main trunk was $30.8 \%$ (4/13). The LAD of one patient with total left main trunk occlusion and good collaterals showed retrograde biphasic flow. The preoperative LAD examination of the 3 patients with total LAD occlusion showed antegrade flow. As Watanabe and associates ${ }^{12}$ reported previously, it is presumed that in these 3 patients the sample volumes were located distal to the collateral input origin. In group $\mathrm{C}$ the factor causing the unsuccessful imaging of the LAD postoperatively is thought to be adhesion induced by surgical intervention. In group D both preoperative and postoperative measurements were unsuccessful, and this was probably due to anatomic factors, such as chest shape, subcutaneous fat, lung adhesion, or emphysema. Our data show that before an emergency operation, this method would be available.

Several studies have reported that in patients who undergo left ITA to LAD bypass, it is useful to evaluate the left ITA graft by means of TTDE for the assessment of graft patency. ${ }^{13-18}$

However, this method has some disadvantages, as follows. First, because the ITA is no longer in its original location in the chest wall and there are many variations in position of the grafted ITA after CABG, the ITA graft could not be easily identified. In part, this is due to the fact that ultrasonography does not penetrate bone or air-filled organs (ie, lungs) ${ }^{15}$ or to variations in the shape of the chest wall. ${ }^{13}$ Second, previous studies have shown that residual flow in the recipient artery might compete with flow in the patent
TABLE 7. Comparison between conventional CABG and OPCAB

\begin{tabular}{|c|c|c|c|}
\hline Variables & $\begin{array}{c}\text { Conventional } \\
\text { CABG } \\
(n=17)\end{array}$ & $\begin{array}{l}\text { OPCAB } \\
(n=8)\end{array}$ & $P$ value \\
\hline \multicolumn{4}{|l|}{ PSV (cm/s) } \\
\hline Before & $15.47 \pm 7.25$ & $13.47 \pm 8.46$ & .57 \\
\hline After & $28.59 \pm 19.66$ & $18.04 \pm 6.25$ & .16 \\
\hline Increase & $13.12 \pm 17.34$ & $4.90 \pm 11.92$ & .27 \\
\hline \multicolumn{4}{|l|}{$\mathrm{MSV}(\mathrm{cm} / \mathrm{s})$} \\
\hline Before & $10.52 \pm 5.57$ & $8.46 \pm 5.15$ & .41 \\
\hline After & $20.76 \pm 14.81$ & $12.59 \pm 5.40$ & .15 \\
\hline Increase & $10.23 \pm 13.38$ & $4.50 \pm 7.33$ & .30 \\
\hline \multicolumn{4}{|l|}{ PDV $(\mathrm{cm} / \mathrm{s})$} \\
\hline Before & $25.09 \pm 12.88$ & $22.36 \pm 12.48$ & .64 \\
\hline After & $54.39 \pm 36.83$ & $36.06 \pm 11.39$ & .19 \\
\hline Increase & $29.30 \pm 39.77$ & $14.41 \pm 11.41$ & .30 \\
\hline \multicolumn{4}{|l|}{$\operatorname{MDV}(\mathrm{cm} / \mathrm{s})$} \\
\hline Before & $15.10 \pm 6.30$ & $14.57 \pm 7.90$ & .87 \\
\hline After & $34.33 \pm 23.90$ & $22.41 \pm 8.77$ & .19 \\
\hline Increase & $19.24 \pm 25.56$ & $8.71 \pm 9.02$ & .31 \\
\hline \multicolumn{4}{|l|}{ DVTI (cm) } \\
\hline Before & $7.45 \pm 2.73$ & $6.70 \pm 3.38$ & .58 \\
\hline After & $17.24 \pm 11.88$ & $12.17 \pm 5.75$ & .27 \\
\hline Increase & $9.79 \pm 11.83$ & $6.09 \pm 8.51$ & .47 \\
\hline \multicolumn{4}{|l|}{ TVTI (cm) } \\
\hline Before & $11.15 \pm 4.23$ & $9.01 \pm 5.02$ & .30 \\
\hline After & $21.20 \pm 14.53$ & $15.41 \pm 6.79$ & .30 \\
\hline Increase & $10.05 \pm 14.63$ & $7.09 \pm 10.68$ & .64 \\
\hline \multicolumn{4}{|l|}{ DSVTIR } \\
\hline Before & $2.82 \pm 1.38$ & $3.71 \pm 1.78$ & .21 \\
\hline After & $5.40 \pm 3.10$ & $4.10 \pm 1.72$ & .29 \\
\hline Increase & $2.58 \pm 3.13$ & $0.58 \pm 2.14$ & .14 \\
\hline
\end{tabular}

Data are presented as mean \pm SD. PSV, Peak systolic velocity; MSV, mean systolic velocity; PDV, peak diastolic velocity; $M D V$, mean diastolic velocity; DVTI, diastolic VTI; TVTI, total VTI; DSVTIR, diastolic-to-systolic VTI ratio.

graft and reduce flow in the graft and that the bypass graft will be occluded or become very thin when a stenotic lesion of the recipient vessel is mild or regressed and when myocardial ischemia in the relevant region is absent. ${ }^{19-21}$ These reports suggest that it is more important to evaluate myocardial perfusion in the $\mathrm{LAD}$ region rather than to evaluate graft patency. Third, ITA graft flow seems to be influenced by its residual branches. Fourth, only assessment of an ITA to LAD graft can be performed by using this method.

On the other hand, our technique has some advantages, as follows. First, because the distal LAD runs in the interventricular groove near the chest wall, it is more easily accessible to imaging by means of transthoracic ultrasonography, even after CABG, and in many cases the location of the LAD remains in its original location after the operation. Thus our technique would provide more accurate information for comparison of LAD flow before and after CABG. Second, in contrast with the assessment of the ITA graft, in which only the left ITA graft to the LAD is available for 
imaging, our method provides for the assessment of any graft to the LAD. Third, because our method evaluates the LAD flow directly, this method would be available without consideration of complicated native flow after multirevascularization by means of CABG, consisting of several grafts, or even after hybrid therapy, consisting of CABG and angioplasty.

\section{Subgroup Analysis: Conventional CABG Versus OPCAB}

We found a tendency for a greater increase in flow after conventional $\mathrm{CABG}$ than after OPCAB in all parameters. OPCAB is associated with temporary myocardial ischemiarelated complications. ${ }^{22,23}$ Temporary snaring of coronary arteries during heart beating and reperfusion after anastomosis might cause a condition that is similar to the noreflow phenomenon. It is documented that in a no-reflow zone myocardial blood flow is reduced and coronary vascular resistance is increased. ${ }^{24}$ These mechanisms are compatible with our data, but further study is necessary to clarify these relationships.

\section{Study Limitations}

First, the study population consisted of only patients with patent grafts. No patient with anastomotic stenosis was included in this study, and the LAD flow pattern in patients with anastomotic stenosis could not be analyzed. Second, we did not perform any other special examinations for the assessment of myocardial perfusion, such as myocardial scintigraphy or dobutamine stress echocardiography. If we had the data of these examinations, the relationship between the LAD flow pattern and myocardial perfusion would be clearer.

\section{Conclusions}

We have described changes in the LAD flow after CABG. Measurement of LAD flow with TTDE could allow noninvasive evaluation of the direct effect of bypass grafting on the coronary circulation.

We thank Mr Yuzo Sakagami, Mr Masakazu Ueda, and Mr Yoshiki Jyonishi for excellent technical assistance. We are also very grateful to Dr Hiroshi Ito for his advice.

\section{References}

1. Fusejima K. Noninvasive measurement of coronary artery blood flow using combined two-dimensional and Doppler echocardiography. J Am Coll Cardiol. 1987;10:1024-31.

2. Kenny A, Sutters M, Evans DB, Shapiro LM. Effects of hemodialysis on coronary blood flow. Am J Cardiol. 1994;74:291-4.

3. Kenny A, Wisbey CR, Shapiro LM. Measurement of left anterior descending coronary artery flow velocities by transthoracic Doppler ultrasound. Am J Cardiol. 1994;73:1021-2.

4. Kenny A, Shapiro LM. Transthoracic high-frequency two-dimensional echocardiography, Doppler and color flow mapping to determine anatomy and blood flow patterns in the distal left anterior descending coronary artery. Am J Cardiol. 1992;69:1265-8.

5. Ross JJ Jr, Ren JF, Land W, Chandrasekaran K, Mintz GS. Transtho- racic high frequency $(7.5 \mathrm{MHz})$ echocardiographic assessment of coronary vascular reserve and its relation to left ventricular mass. $J$ Am Coll Cardiol. 1990;16:1393-7.

6. Hozumi T, Yoshida K, Ogata Y, Akasaka T, Asami Y, Takagi T, et al. Noninvasive assessment of significant left anterior descending coronary artery stenosis by coronary flow velocity reserve with transthoracic color Doppler echocardiography. Circulation. 1998;97:1557-62.

7. Higashiue S, Watanabe H, Yokoi Y, Takeuchi K, Yoshikawa J. Simple detection of severe coronary stenosis using transthoracic Doppler echocardiography at rest. Am J Cardiol. 2001;87:1064-8.

8. Crowley JJ, Shapiro LM. Noninvasive analysis of coronary artery poststenotic flow characteristics by using transthoracic echocardiography. J Am Soc Echocardiogr. 1998;11:1-9.

9. Minagoe S. Transthoracic Doppler echocardiographic assessment of left anterior descending coronary artery and intramyocardial small coronary artery flow in patients with hypertrophic cardiomyopathy. J Cardiol. 2001;37(suppl 1):115-20.

10. Pizzuto F, Voci P, Mariano E, Puddu PE, Sardella G, Nigri A. Assessment of flow velocity reserve by transthoracic Doppler echocardiography and venous adenosine infusion before and after left anterior descending coronary artery stenting. J Am Coll Cardiol. 2001;38:155-62.

11. Takeuchi M, Miyazaki C, Yoshitani H, Otani S, Sakamoto K, Yoshikawa J. Assessment of coronary flow velocity with transthoracic Doppler echocardiography during dobutamine stress echocardiography. J Am Coll Cardiol. 2001;38:117-23.

12. Watanabe N, Akasaka T, Yamaura Y, Akiyama M, Koyama Y, Kamiyama $\mathrm{N}$, et al. Noninvasive detection of total occlusion of the left anterior descending coronary artery with transthoracic Doppler echocardiography. J Am Coll Cardiol. 2001;38:1328-32.

13. Crowley JJ, Shapiro LM. Noninvasive assessment of left internal mammary artery graft patency using transthoracic echocardiography. Circulation. 1995;92(suppl):II25-30.

14. Fusejima K, Takahara Y, Sudo Y, Murayama H, Masuda Y, Inagaki Y. Comparison of coronary hemodynamics in patients with internal mammary artery and saphenous vein coronary artery bypass grafts: a noninvasive approach using combined two-dimensional and Doppler echocardiography. J Am Coll Cardiol. 1990;15:131-9.

15. Canver CC, Armstrong VM, Nichols RD, Mentzer RM Jr. Color-flow duplex ultrasound assessment of internal thoracic artery graft after coronary bypass. Ann Thorac Surg. 1995;59:389-92.

16. Driever R, Fuchs S, Schmitz E, Vetter HO. Assessment of left mammary artery grafts (LIMA) to left anterior descending artery (LAD) after off-pump coronary artery bypass grafting by color Doppler. Cardiovasc Surg. 2002;10:49-51.

17. van Son JA, Skotnicki SH, Peters MB, Pijls NH, Noyez L, van Asten WN. Noninvasive hemodynamic assessment of the internal mammary artery in myocardial revascularization. Ann Thorac Surg. 1993;55:404-9.

18. Nasu M, Akasaka T, Okazaki T, Nasu M, Akasaka T, Okazaki T, et al. Postoperative flow characteristics of left internal thoracic artery grafts. Ann Thorac Surg. 1995;59:154-62.

19. Seki T, Kitamura S, Kawachi K, Morita R, Kawata T, Mizuguchi K, et al. A quantitative study of postoperative luminal narrowing of the internal thoracic artery graft in coronary artery bypass surgery. $J$ Thorac Cardiovasc Surg. 1992;1046:1532-8.

20. Kitamura S, Kawachi K, Seki T, Sawabata N, Morita R, Kawata T. Angiographic demonstration of no-flow anatomical patency of internal thoracic-coronary artery bypass grafts. Ann Thorac Surg. 1992;531:156-9.

21. Dincer B, Barner HB. The "occluded" internal mammary artery graft: restoration of patency after apparent occlusion associated with progression of coronary disease. J Thorac Cardiovasc Surg. 1983;852: 318-20.

22. D'Ancona G, Donias HW, Bergsland J, Karamanoukian HL. Myocardial stunning after off-pump coronary artery bypass grafting: safeguards and pitfalls. Ann Thorac Surg. 2001;72:2182-3.

23. Grubitzsch H, Ansorge K, Wollert HG, Eckel L. Stunned myocardium after off-pump coronary artery bypass grafting. Ann Thorac Surg. 2001;71:352-5.

24. Rezkalla SH, Kloner RA. No-reflow phenomenon. Circulation. 2002; 105:656-62. 